\section{Commentary: Safety first!}

\author{
Betty C. Tong, MD, MHS
}

It has been well established by the results of the National Lung Screening Trial and the NELSON (NederlandsLeuvens Longkanker Screenings Onderzoek) trial that the use of low-dose computed tomography (LDCT) for lung cancer screening in high-risk patients is effective in reducing lung cancer-related mortality. ${ }^{1,2}$ Paramount to the mandatory shared decision-making conducted before LDCT imaging, however, is a discussion of the benefits and risks that are associated with LDCT screening. Not surprisingly, information about lung cancer-screening programs readily available to patients is disproportionately skewed toward only the benefits of screening. ${ }^{3}$ This imbalance provides a disservice to those of us involved in the diagnosis and treatment of lung cancer, as we are all well aware that no treatment or procedure is $100 \%$ safe and risk free. In the accompanying study, however, Ho and colleagues ${ }^{4}$ demonstrate that high levels of safety are achievable in a busy lung cancer-screening program, with minimal harm to their patient population.

It is important to note several points. First, not all patients with suspicious findings (as designated by LungRADS 4, or LR4) underwent an invasive diagnostic procedure. That is, "suspicious" (LR4) does not equate to "malignant." In fact, only 93 of the 311 patients who were designated as LR4 were ultimately diagnosed with primary lung cancer.

Notably, 14 of 83 patients $(16.9 \%)$ in the study underwent surgery for benign disease. At first glance, this proportion seems high. However, it is consistent with other published series. Moreover, although it might be easy to label these operations as "unnecessary," the amount of patient

\footnotetext{
From the Division of Thoracic and Cardiovascular Surgery, Duke University Medical Center, Durham, NC.

Disclosures: The author serves as a consultant for Medtronic, Inc. She is a member of the National Comprehensive Cancer Network Lung Cancer Screening Guidelines committee (no compensation)

The Journal policy requires editors and reviewers to disclose conflicts of interest and to decline handling or reviewing manuscripts for which they may have a conflict of interest. The editors and reviewers of this article have no conflicts of interest.

Received for publication Sept 2, 2020; revisions received Sept 2, 2020; accepted for publication Sept 3, 2020; available ahead of print Sept 11, 2020.

Address for reprints: Betty C. Tong, MD, MHS, Division of Thoracic and Cardiovascular Surgery, Duke University Medical Center, Durham, NC 27710 (E-mail: betty. tong@duke.edu).

J Thorac Cardiovasc Surg 2021;161:803-4

$0022-5223 / \$ 36.00$

Copyright (c) 2020 by The American Association for Thoracic Surgery

https://doi.org/10.1016/j.jtcvs.2020.09.017
}

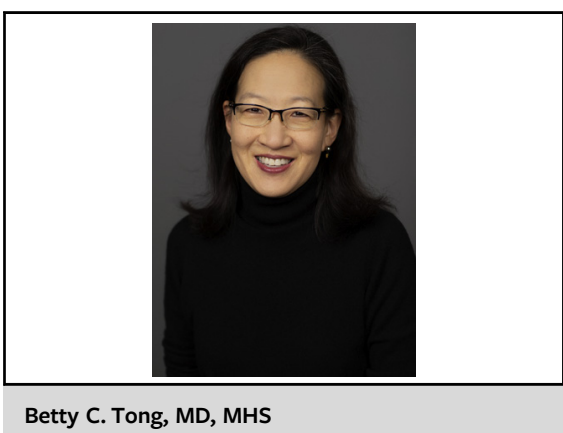

CENTRAL MESSAGE

In a multidisciplinary and highquality program, low-dose CT lung cancer screening is safe and effective, with minimal patient harm.

distress associated with "scanxiety" in our patient population is real. ${ }^{5}$ This is avoided with the knowledge that the pathologic diagnoses associated with the suspicious imaging findings were indeed benign.

Finally, the authors used best practices in managing the patients with lung cancer diagnoses. In the surgical cohort, minimally invasive techniques were adopted for the majority of patients; this is especially important when considering the proportion of benign diagnoses in the cohort. All but 1 patient who received stereotactic body radiation did so only after being evaluated by a thoracic surgeon as part of the multidisciplinary team.

Currently, lung cancer screening use in eligible patients ranges from only $4 \%$ to $14 \%$ in the United States ${ }^{6,7}$; these rates lag far below screening use for cervical, breast, and colorectal cancer, which nears $60 \%{ }^{8}$ The outcomes of this study show that, in a high-quality screening program, ${ }^{9}$ low-dose CT lung cancer screening is safe and effective. With multidisciplinary review of suspicious findings and consensus recommendations for action, patients can be assured of best practices and minimal "unnecessary" harm as a result of undergoing these studies. What is gained by doing so is appropriate management of lung cancer and other malignancies, and peace of mind that the time and effort put forth into lung cancer screening is worthwhile.

\section{References}

1. de Koning HJ, van der Aalst CM, de Jong PA, Scholten ET, Nackaerts K, Heuvelmans MA, et al. Reduced lung-cancer mortality with volume CT screening in a randomized trial. N Engl J Med. 2020;382:503-13. 
2. National Lung Screening Trial Research Team. Reduced lung-cancer mortality with low-dose computed tomographic screening. N Engl J Med. 2011;365:395-409.

3. Clark SD, Reuland DS, Enyioha C, Jonas DE. Assessment of lung cancer screening program websites. JAMA Intern Med. 2020;180:824-30.

4. Ho H, Williamson C, Regis SM, Stock CT, Quardri SM, McKee BJ, et al. Surgery and invasive diagnostic procedures for benign disease are rare in a large low-dose computed tomography lung cancer screening program. J Thorac Cardiovasc Surg. 2021;161:790-802.e2.

5. Bauml JM, Troxel A, Epperson CN, Cohen RB, Schmitz K, Stricker C, et al. Scanassociated distress in lung cancer: 1uantifying the impact of "scanxiety" Lung Cancer. 2016;100:110-3.
6. Tailor TD, Tong BC, Gao MJ, Henderson LM, Choudhury KR, Rubin GD. Use of lung cancer screening in the Medicare fee-for-service population. Chest. June 17, 2020 [Epub ahead of print].

7. Zahnd WE, Eberth JM. Lung cancer screening utilization: a behavioral risk factor surveillance system analysis. Am J Prev Med. 2019;57:250-5.

8. Sabatino SA, White MC, Thompson TD, Klabunde CN. Cancer screening test use-United States, 2013. MMWR Morb Mortal Wkly Rep. 2015;464-8.

9. Mazzone P, Powell CA, Arenberg D, Bach P, Detterbeck F, Gould MK, et al. Components necessary for high-quality lung cancer screening: American College of Chest Physicians and American Thoracic Society Policy Statement. Chest. 2015;147:295-303.
See Article page 790.

\section{Commentary: We need more surgeons!}

\section{Daniel P. Raymond, MD}

Many remember the release of the National Lung Screening Trial $^{1}$ and the excitement it generated. What followed was a flurry of planning in anticipation of a huge influx of lung nodules patient requiring multidisciplinary management. I personally remember discussions about increasing surgical resources to handle the surge in patients, even recruiting new surgeons! Unfortunately, that surge was more of a trickle. Even after the Centers for Medicare and Medicaid Services approved lung cancer screening (LCS) as a benefit in 2015, the prevalence of screening in appropriate populations remains $<20 \%{ }^{2}$

Ho and colleagues ${ }^{2}$ take an in-depth look at a reason for this poor performance-concern regarding unnecessary invasive procedures - in their recent study. They first point out the evolution of LCS since the original release of the NLST trial 9 years ago. Their program has adopted the use of Lung CT Screening Reporting \& Data System for nodule reporting, which has increased the positive predictive value 2.5 -fold. In combination with the standardization

From Lerner College of Medicine, Cleveland Clinic Thoracic \& Cardiovascular Surgery, Cleveland, Ohio.

Disclosures: The author reported no conflicts of interest.

The Journal policy requires editors and reviewers to disclose conflicts of interest and to decline handling or reviewing manuscripts for which they may have a conflict of interest. The editors and reviewers of this article have no conflicts of interest.

Received for publication Aug 20, 2020; revisions received Aug 20, 2020; accepted for publication Aug 20, 2020; available ahead of print Aug 29, 2020.

Address for reprints: Daniel P. Raymond, MD, Lerner College of Medicine, Cleveland Clinic Thoracic \& Cardiovascular Surgery, 9500 Euclid Ave, J4-1, Cleveland, OH 44195 (E-mail: raymond3@ccf.org).

J Thorac Cardiovasc Surg 2021;161:804-5

$0022-5223 / \$ 36.00$

Copyright (c) 2020 by The American Association for Thoracic Surgery

https://doi.org/10.1016/j.jtcvs.2020.08.073
Check for updates

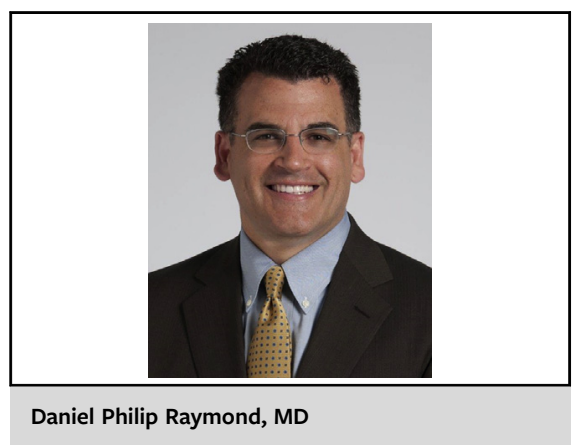

CENTRAL MESSAGE

The risk of unnecessary invasive

procedures for benign disease

due to lung cancer screening is

$<1 \%$.

of a multidisciplinary approach, this has resulted in a significant decrease in the use of invasive tests from roughly $10 \%$ in the NLST to $2.6 \%$ in the current trial. As a result, the ultimate probability of undergoing any invasive procedure for nonmalignant disease in a screened patient was $0.95 \%$; surgery was $0.43 \%$.

When counseling patients, what do we say? The benefit of LCS is well documented. If the patient or practitioner expresses concern about unnecessary testing, we now have excellent data to allay those fears. Based on this study, $30 \%$ of patients with a Lung CT Screening Reporting \& Data System category 4 will have a malignancy. The probability of an unnecessary invasive test using the Lahey system to evaluate that malignancy is $<1 \%$. With additional testing and clinical judgment, if an invasive diagnostic test is deemed necessary, the chances of cancer rise to roughly $50 \%$. Of those tests, a disappointingly low number $(6 \%)$ will reveal a specific benign diagnosis, 